\title{
Mechanical ventilation strategies for intensive care unit patients without acute lung injury or acute respiratory distress syndrome: a systematic review and network meta-analysis
}

\author{
Lei Guo ${ }^{\dagger}$, Weiwei Wang ${ }^{\dagger}$, Nana Zhao, Libo Guo, Chunjie Chi, Wei Hou, Anqi Wu, Hongshuang Tong, Yue Wang, \\ Changsong Wang ${ }^{*}$ and Enyou Li ${ }^{*}$
}

\begin{abstract}
Background: It has been shown that the application of a lung-protective mechanical ventilation strategy can improve the prognosis of patients with acute lung injury (ALI) or acute respiratory distress syndrome (ARDS). However, the optimal mechanical ventilation strategy for intensive care unit (ICU) patients without ALI or ARDS is uncertain. Therefore, we performed a network meta-analysis to identify the optimal mechanical ventilation strategy for these patients.

Methods: We searched the Cochrane Central Register of Controlled Trials (CENTRAL) in the Cochrane Library, EMBASE, MEDLINE, CINAHL, and Web of Science for studies published up to July 2015 in which pulmonary compliance or the partial pressure of arterial oxygen/fraction of inspired oxygen $\left(\mathrm{PaO}_{2} / \mathrm{FlO}_{2}\right)$ ratio was assessed in ICU patients without ALI or ARDS, who received mechanical ventilation via different strategies. The data for study characteristics, methods, and outcomes were extracted. We assessed the studies for eligibility, extracted the data, pooled the data, and used a Bayesian fixed-effects model to combine direct comparisons with indirect evidence.

Results: Seventeen randomized controlled trials including a total of 575 patients who received one of six ventilation strategies were included for network meta-analysis. Among ICU patients without ALI or ARDS, strategy $C$ (lower tidal volume $(V T)+$ higher positive end-expiratory pressure (PEEP)) resulted in the highest $\mathrm{PaO}_{2} / \mathrm{FIO}_{2}$ ratio; strategy $\mathrm{B}$ (higher $\mathrm{VT}+$ lower PEEP) was associated with the highest pulmonary compliance; strategy A (lower VT + lower PEEP) was associated with a shorter length of ICU stay; and strategy D (lower $\mathrm{VT}+$ zero end-expiratory pressure (ZEEP)) was associated with the lowest $\mathrm{PaO}_{2} / \mathrm{FiO}_{2}$ ratio and pulmonary compliance.
\end{abstract}

Conclusions: For ICU patients without ALI or ARDS, strategy C (lower VT + higher PEEP) was associated with the highest $\mathrm{PaO}_{2} / \mathrm{FiO}_{2}$ ratio. Strategy $\mathrm{B}$ (higher $\mathrm{VT}+$ lower $\mathrm{PEEP}$ ) was superior to the other strategies in improving pulmonary compliance. Strategy A (lower VT + lower PEEP) was associated with a shorter length of ICU stay, whereas strategy $\mathrm{D}$ (lower $\mathrm{VT}+\mathrm{ZEEP}$ ) was associated with the lowest $\mathrm{PaO}_{2} / \mathrm{FiO}_{2}$ ratio and pulmonary compliance.

Keywords: Ventilation strategies, ICU patients without ALI or ARDS, Network meta-analysis, Pulmonary compliance, $\mathrm{PaO}_{2} / \mathrm{FlO}_{2}$ ratio

\footnotetext{
* Correspondence: changsongwang@aliyun.com; enyouli@aliyun.com

${ }^{\dagger}$ Equal contributors

Department of Anesthesiology, The First Affiliated Hospital of Harbin Medical

University, No 23 Youzheng St., Nangang District, Harbin, Heilongjiang

150001, China
} 


\section{Background}

It has been shown that the application of lung-protective mechanical ventilation with a low tidal volume can improve the prognosis of patients with acute lung injury (ALI) or acute respiratory distress syndrome (ARDS) [1-3]. Several clinical studies have attempted to optimize the ventilator management strategy to improve oxygenation and lung compliance, thereby reducing the length of intensive care unit (ICU) stay and the mortality of ICU patients without ALI or ARDS [4-6]. However, the optimal mechanical ventilation strategy for ICU patients without ALI or ARDS is uncertain.

Clinical data show that patients without a diagnosis of ALI or ARDS can benefit ventilation with a low tidal volume [4, 7]. Schultz et al. [7] concluded that the initial ventilator setting, high tidal volume, may be associated with lung injury in patients without ALI or ARDS. Serpa Neto et al. [8] used a traditional pairwise meta-analysis to systematically evaluate ventilation strategies such as high and low tidal volume. Their conclusions were as follows: compared to ventilation with a higher tidal volume, protective ventilation with lower tidal volumes at the onset of mechanical ventilation was associated with better clinical outcomes, including a shorter length of hospital stay, lower mortality, fewer pulmonary infections, and less atelectasis, among patients without ALI or ARDS.

In addition to tidal volume, there are other factors in the overall ventilation strategy, such as positive endexpiratory pressure (PEEP), recruitment maneuver (RM), and respiratory ratio. Tidal volume and PEEP play important roles. However, traditional pairwise metaanalysis can only be used to compare specific factors between ventilation strategies and cannot be used to compare the entire set of parameters relevant to different ventilation strategies. Therefore, tidal volume and clinical outcomes of different comprehensive ventilation strategies using a specific tidal volume and PEEP cannot be compared by traditional pairwise meta-analysis. Accordingly, the results obtained from traditional pairwise meta-analyses have significant limitations. Fortunately, a network meta-analysis is advantageous for the evaluation of the comparative effectiveness of multiple interventions, even when some parameters might not have been directly compared. Additionally, network meta-analysis has the potential to reduce the uncertainty in treatment effect estimates $[9,10]$. Given these advantages, we used a network meta-analysis to search the literature for data examining the optimal tidal volume and PEEP in patients without ALI or ARDS. Based on these data, we divided the ventilation mode into six types and considered each ventilation mode as a unique ventilation strategy. Subsequently, the effectiveness and safety of various ventilation strategies were compared to identify the optimal ventilation strategy for ICU patients without ALI or ARDS.

\section{Methods}

We conducted our systematic review in accordance with the methods recommended in the Preferred Reporting Items for Systematic Reviews and Meta-Analyses (PRISMA) guidelines [11].

\section{Literature search}

The trials were identified through electronic and manual searches. We searched the Cochrane Central Register of Controlled Trials (CENTRAL) in the Cochrane Library, EMBASE, MEDLINE, CINAHL, and Web of Science using a combination of MeSH terms and text words. We did not restrict our search based on language or year of publication. The most recent search date was July 2015. We reviewed the reference lists of published metaanalyses. In addition, we manually searched the bibliographies of randomized controlled trials, meta-analyses, and systematic reviews for relevant studies that may have been missed in the initial electronic search.

\section{Inclusion and exclusion criteria}

The study inclusion and exclusion process was conducted separately by two groups. When there was a discrepancy between the two groups, the selection committee met to reach a consensus on the inclusion or exclusion of the disputed article. We first excluded the following types of articles: reviews, retrospective studies, observational studies, case reports, animal studies, studies conducted on children, studies examining only psychological mechanisms, unrelated studies (such as studies of mechanical ventilation in patients with ARDS), duplicate reports, studies involving repeated experiments (commentary articles on specific studies or secondary analyses of experimental data), and nonrandomized trials. Ultimately, randomized controlled trials examining mechanical ventilation in ICU patients without ALI or ARDS were included. All of the included studies were of relatively high quality with a low risk of bias. No studies were excluded because of quality concerns.

\section{Outcome measures and data extraction}

The extracted data included basic study information such as the experimental design, experimental period, country of the study, inclusion criteria, age and gender of the included patients, detailed experimental procedures, specific mechanical ventilation settings, clinical outcomes, and safety outcomes of the patients. The primary outcome of this study was the $\mathrm{PaO}_{2} / \mathrm{FiO}_{2}$ ratio. If multiple $\mathrm{PaO}_{2} / \mathrm{FiO}_{2}$ ratios were presented in a report, 
the last result was used. The secondary outcomes of this study were pulmonary compliance and the duration of ICU stay. Two groups extracted the data separately and then performed comparison and verification together. If necessary, we contacted the corresponding authors to seek assistance in the case of missing data and sent a table containing the extracted data to those authors for supplementary data or verification.

\section{Ventilation strategies}

In this network meta-analysis, the parameters of ventilation strategies for ICU patients without ARDS were specified. Lower PEEP was defined as PEEP lower than 10 $\mathrm{mmHg}$, and higher PEEP was defined as PEEP higher than or equal to $10 \mathrm{mmHg}$ [12]. Lower tidal volume was defined as lower than or equal to $8 \mathrm{ml}$ per $\mathrm{kg}$ predicted body weight, and higher tidal volume was defined higher than $8 \mathrm{ml}$ per $\mathrm{kg}$ predicted body weight [13]. Accordingly, six ventilation strategies were obtained (Table 1).

\section{Statistical analysis}

Network meta-analysis combines the direct and indirect evidence for all relative treatment effects and provides estimates with maximum power [14-16]. A network meta-analysis was performed using the GeMTC [17] package in $\mathrm{R}$ (i386 3.0.2). In this analysis, to maximize accuracy and power, the mean difference (MD) and $95 \%$ confidence intervals were used to evaluate the effect of each mechanical ventilation strategy on pulmonary compliance and the $\mathrm{PaO}_{2} / \mathrm{FiO}_{2}$ ratio of ICU patients without ARDS or ALI [18]. A difference was considered statistically significant when the range of the $95 \%$ confidence intervals did not include zero.

Model selection was based on the Dias guidelines [19] for evaluating linear models. Dbar denotes the posterior mean of the residual deviance; $\mathrm{pD}$ denotes the effective number of parameters (leverage); and DIC denotes the deviance information criterion. A smaller Dbar value indicates a better model fit. However, the model with the lowest DIC is generally chosen to aid the interpretation by accounting for model complexity. A lower DIC value

Table 1 Six ventilation strategies for intensive care unit patients without ALI or ARDS

\begin{tabular}{ll}
\hline & Strategy \\
\hline A & Lower tidal volume and lower PEEP (lower VT + lower PEEP) \\
B & Higher tidal volume and lower PEEP (higher VT + lower PEEP) \\
C & Lower tidal volume and higher PEEP (lower VT + higher PEEP) \\
D & Lower tidal volume (lower VT + ZEEP) \\
E & Higher tidal volume (higher VT+ ZEEP) \\
F & Higher tidal volume and higher PEEP (higher VT + higher PEEP) \\
\hline
\end{tabular}

Lower positive end-expiratory pressure (PEEP) $<10 \mathrm{mmHg}$; higher PEEP $\geq 10 \mathrm{mmHg}$; lower tidal volume $(\mathrm{VT}) \leq 8 \mathrm{ml} / \mathrm{kg}$; higher VT $>8 \mathrm{ml} / \mathrm{kg}$. ZEEP zero end-expiratory pressure indicates a better model fit. Differences between the models of less than 3 to 5 were not considered significant [20]. The models were run for 150,000 iterations, and convergence was assessed using the BrooksGelman-Rubin diagnostic approach [21]. We used a technique referred to as "back-calculation" [22] to evaluate the consistency of the findings of the network meta-analysis based on direct versus indirect evidence. During this process, three types of models were estimated: unrelated study effects, unrelated mean effects, and consistency.

The output of the summary function can be plotted for a visual representation. We investigated the possibility of statistical heterogeneity and inconsistency between the direct and indirect effect estimates by visually inspecting the forest plots and the $I^{2}$ statistic using the Higgins-Thompson method (low heterogeneity $25 \%$, moderate $50 \%$, and high $75 \%$ ) [23]. We also ranked the different interventions in terms of their likelihood of leading to the best results for each outcome [12]. In the Markov chain Monte Carlo cycle, each ventilation strategy was ranked based on the estimated effect size. These probabilities summed to 1 for each treatment and each rank. $X \%$ means that the strategy achieves $x \%$ effectiveness. Thus, a higher percentage denotes a more effective intervention, although this ranking refers to only the considered possibilities rather than the actual effectiveness of a given ventilation strategy [18].

\section{Results}

We identified 28,160 studies for review based on their titles and abstracts (Fig. 1). After an initial screen, we retrieved the full texts of 86 potentially eligible articles for a detailed assessment. Ultimately, we excluded 75 irrelevant full-text articles (Additional file 1), and 11 randomized controlled trials [4, 24-33] were included in the network meta-analysis. These studies included 575 patients who received one of six ventilation modes (Table 1). Unfortunately, ventilation strategies $\mathrm{E}$ (higher VT + ZEEP) and $\mathrm{F}$ (higher VT + higher PEEP) were isolated from the other ventilation strategies. Therefore, only the other four ventilation strategies were compared. All of the included studies were randomized controlled trials (Table 2).

\section{Heterogeneity}

In this network meta-analysis, six studies reported data on the $\mathrm{PaO}_{2} / \mathrm{FIO}_{2}$ ratio and were included in the metaanalysis. These studies were two-arm trials. The comparison between these studies showed no heterogeneity (Additional file 2A). Among all of the included studies, pulmonary compliance was reported in three articles. These studies were two-arm trials, and the comparison between these studies did not show any heterogeneity (Additional file 2B). 
Flow diagram of the literature search
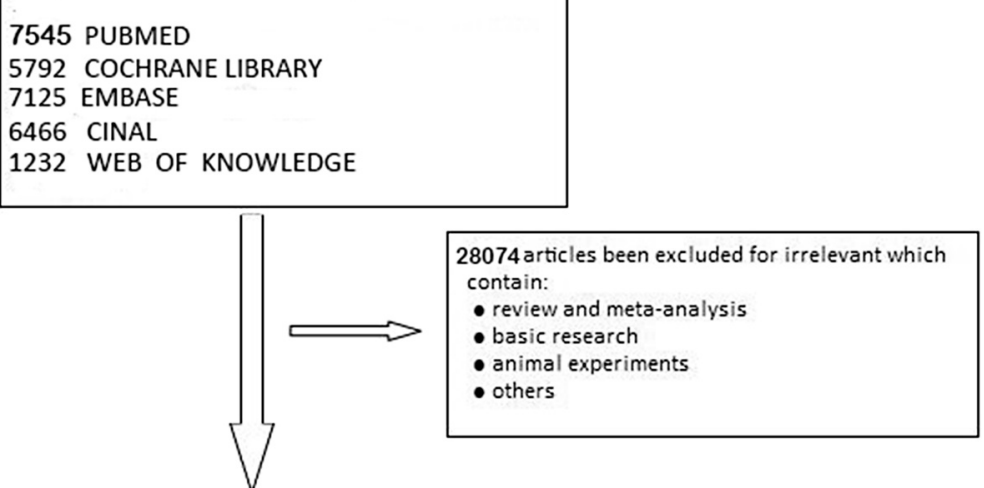

86 full papers or conferences proceeding reviewed
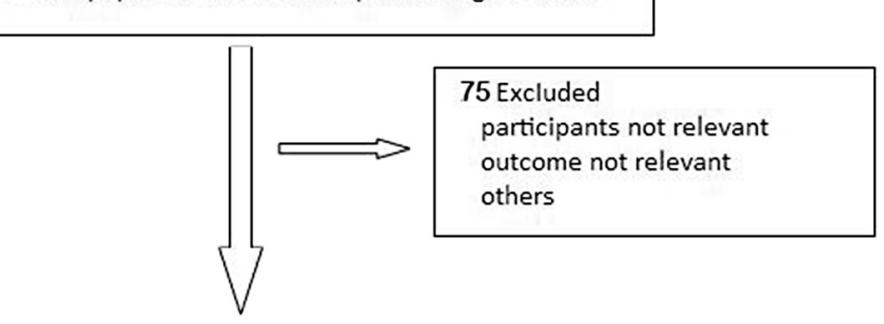

11 included in meta-analysis

Fig. 1 Flow diagram of the literature search

\section{$\mathrm{PaO}_{2} / \mathrm{FIO}_{2}$ ratio}

Six articles reported the $\mathrm{PaO}_{2} / \mathrm{FIO}_{2}$ ratio [24-27, 32, 33]. We chose a fixed-effects model (Additional file 3A) to evaluate the MDs in the overall effect sizes between the four compared ventilation strategies (Fig. 2). The $\mathrm{PaO} 2 / \mathrm{FIO} 2$ ratios, MD values and $95 \%$ confidence intervals of various ventilation strategies are shown in Additional file 4A.

pt?>For probability ranking: in the rankings of the compared ventilation strategies in terms of the $\mathrm{PaO}_{2} /$ $\mathrm{FIO}_{2}$ ratio (Additional file 5A), we found that strategy $\mathrm{C}$ (lower VT + higher PEEP) had the greatest potential to improve the $\mathrm{PaO}_{2} / \mathrm{FIO}_{2}$ ratio; the probability of strategy $\mathrm{C}$ holding the top ranking was $98.8 \%$. Strategy D (lower $\mathrm{VT}+\mathrm{ZEEP}$ ) was estimated to be the worst strategy in terms of the $\mathrm{PaO}_{2} / \mathrm{FIO}_{2}$ ratio.

For direct and indirect comparison: compared to strategies B (higher VT + lower PEEP), A (lower VT + lower PEEP), and D (lower VT + ZEEP), strategy C (lower VT + higher PEEP) had the greatest potential to improve the $\mathrm{PaO}_{2} / \mathrm{FIO}_{2}$ ratio; the respective MDs (95\% confidence intervals) were $-46.2(-78.6,-13.7),-60.9(-98.6,-23.1)$, and -121 (-221, -20.6) (Fig. 3).

\section{Pulmonary compliance}

Three articles [25-27] reported on pulmonary compliance and examined four ventilation strategies (Fig. 4). We chose a fixed-effects model (Additional file 3B) to evaluate the MDs in the overall effect sizes. MD values and $95 \%$ confidence intervals of various ventilation strategies are shown in Additional file 4B.

For probability ranking: we summarized the rankings of the compared ventilation strategies in terms of pulmonary compliance (Additional file 5B). Ventilation strategy B (higher VT + lower PEEP) had the greatest potential to improve pulmonary compliance; the probability of strategy B holding the top ranking was $57.2 \%$, followed by strategy $C$ (lower $\mathrm{VT}+$ higher PEEP) at $42.7 \%$. Strategy D (lower VT + ZEEP) was estimated to be the worst strategy in terms of pulmonary compliance.

For direct and indirect comparison: compared to ventilation strategy $\mathrm{D}$ (lower $\mathrm{VT}+\mathrm{ZEEP})$, strategies $\mathrm{A}$ (lower VT + lower PEEP), B (higher VT + lower PEEP), and $\mathrm{C}$ (lower VT + higher PEEP) were associated with an improvement in lung compliance; the respective MDs (95\% confidence intervals) were $24(13,25), 34(16,52)$, and 32 (20, 45) (Fig. 5). 
Table 2 Characteristics of intensive care unit patients without acute lung injury or acute respiratory distress syndrom included in randomized controlled trials

\begin{tabular}{|c|c|c|c|c|c|c|c|c|c|c|c|}
\hline \multirow[t]{2}{*}{ Study } & \multirow[t]{2}{*}{ Country } & \multirow[t]{2}{*}{ Research period } & \multirow{2}{*}{$\begin{array}{l}\text { Ventilation } \\
\text { strategies }\end{array}$} & \multirow[t]{2}{*}{ Patients ( $n$ ) } & \multirow[t]{2}{*}{ Cause } & \multirow{2}{*}{$\begin{array}{l}\text { Study quality } \\
\text { assessment, } \\
\text { Jadad scale }\end{array}$} & \multicolumn{5}{|l|}{ Results } \\
\hline & & & & & & & $\mathrm{PaO} 2 / \mathrm{FlO} 2$ & $\begin{array}{l}\text { Lung compliance } \\
(\mathrm{ml} / \mathrm{cmH} 2 \mathrm{O})\end{array}$ & Deaths $(n)$ & $\begin{array}{l}\text { Length of ICU } \\
\text { stay (days) }\end{array}$ & $\begin{array}{l}\text { Length of } \\
\text { hospital } \\
\text { stay (days) }\end{array}$ \\
\hline Lee PC [24] 1990 & USA & 10/1987-02/1988 & $\begin{array}{l}\text { A (lower VT + lower } \\
\text { PEEP) vs B (higher } \\
V T+\text { lower PEEP) }\end{array}$ & 103 & $\begin{array}{l}\text { Multiple trauma } \\
\text { or celiotomy }\end{array}$ & 5 & $\begin{array}{l}294 \pm 86 / \\
260 \pm 78\end{array}$ & NR & NR & $\begin{array}{l}4.6 \pm 1 / \\
2.7 \pm 0.5\end{array}$ & NR \\
\hline Borges DL [25] 2013 & Brazil & $01 / 2011-03 / 2012$ & $\begin{array}{l}\text { A (lower VT + lower } \\
\text { PEEP) vs C (lower } \\
V T+\text { higher PEEP) }\end{array}$ & 89 & CABG surgery & 6 & $\begin{array}{l}270 \pm 90 / \\
328.25 \pm \\
84.75\end{array}$ & $\begin{array}{l}47.4 \pm 12.5 / \\
55.8 \pm 19.1\end{array}$ & NR & NR & NR \\
\hline Dyhr T [26] 2002 & Denmark & NR & $\begin{array}{l}\text { A (lower VT + lower } \\
\text { PEEP) vs D (lower } \\
V T+Z E E P)\end{array}$ & 15 & CABG surgery & 7 & $\begin{array}{l}379.5 \pm 90 / \\
304.5 \pm 97.5\end{array}$ & $\begin{array}{l}58 \pm 11 / \\
34 \pm 10\end{array}$ & NR & NR & NR \\
\hline Chaney MA [27] 2000 & America & NR & $\begin{array}{l}\text { B (higher VT + lower } \\
\text { PEEP) vs A (lower } \\
V T+\text { lower PEEP) }\end{array}$ & 25 & CABG surgery & 5 & $\begin{array}{l}368.6 \pm 93.6 / \\
395.1 \pm 179.6\end{array}$ & $\begin{array}{l}58 \pm 11.4 / \\
48.2 \pm 23\end{array}$ & NR & NR & NR \\
\hline Wrigge H [28] 2005 & Germany & NR & $\begin{array}{l}\text { B (higher VT + lower } \\
\text { PEEP) vs C (lower } \\
V T+\text { higher } \\
\text { PEEP) }\end{array}$ & 44 & CABG surgery & 6 & NR & NR & NR & $\begin{array}{l}1.2 \pm 0.5 / \\
2.1 \pm 0.5\end{array}$ & NR \\
\hline Koutsoukou A [29] 2006 & Greece & 2005 & $\begin{array}{l}\text { D (lower VT+ ZEEP) } \\
\text { vs A (lower VT + } \\
\text { lower PEEP) }\end{array}$ & 21 & $\begin{array}{l}\text { Severe brain } \\
\text { damage }\end{array}$ & 6 & NR & NR & NR & NR & NR \\
\hline Good JT Jr [30] 1979 & America & NR & $\begin{array}{l}\text { B (higher VT + lower } \\
\text { PEEP) Vs E (higher } \\
\text { VT + ZEEP) }\end{array}$ & 24 & $\begin{array}{l}\text { Open heart } \\
\text { surgery }\end{array}$ & 7 & NR & NR & NR & NR & NR \\
\hline Marvel SL [31] 1986 & America & 1983 & $\begin{array}{l}\text { E (higher VT + ZEEP) vs } \\
\text { B (higher VT + lower } \\
\text { PEEP) } \\
\text { Vs F (higher VT + higher } \\
\text { PEEP) }\end{array}$ & 44 & CABG surgery & 7 & NR & NR & NR & NR & $\begin{array}{l}8.9 \pm 0.4 / \\
8.8 \pm 0.5\end{array}$ \\
\hline Zupancich E [32] 2005 & Italy & NR & $\begin{array}{l}\text { B (higher VT + lower } \\
\text { PEEP) vs C (lower VT + } \\
\text { higher PEEP) }\end{array}$ & 40 & CABG surgery & 6 & $\begin{array}{l}324 \pm 120 / \\
344 \pm 94\end{array}$ & NR & NR & NR & NR \\
\hline $\begin{array}{l}\text { Pinheiro deOliveira R } \\
\text { [33] } 2010\end{array}$ & Brazil & NR & $\begin{array}{l}\text { B (higher VT + lower } \\
\text { PEEP) Vs A (lower VT + } \\
\text { lower PEEP) }\end{array}$ & 20 & $\begin{array}{l}\text { Surgery and } \\
\text { trauma }\end{array}$ & 6 & $\begin{array}{l}334.25 \pm 82.3 / \\
299.5 \pm 71.9\end{array}$ & NR & $4 / 3$ & $\begin{array}{l}6.5 \pm 5 / \\
7.7 \pm 7.6\end{array}$ & NR \\
\hline Determann RM [4] 2010 & Netherlands & 01/2005-12/2007 & $\begin{array}{l}E \text { (higher VT + ZEEP) } \\
\text { vs D (lower VT+ ZEEP) }\end{array}$ & 150 & $\begin{array}{l}\text { Neurosurgery/ } \\
\text { neurology, } \\
\text { cardiothoracic } \\
\text { surgery, } \\
\text { and cardiology }\end{array}$ & 7 & NR & NR & $23 / 24$ & NR & NR \\
\hline
\end{tabular}

The ventilation strategies are described in "Table 1". PaO2/FIO2 partial pressure of arterial oxygen/fraction of inspired oxygen, PEEP positive end-expiratory pressure, VT tidal volume, ZEEP zero end-expiratory pressure, $N R$ no result reported, $C A B G$ coronary artery bypass graft 


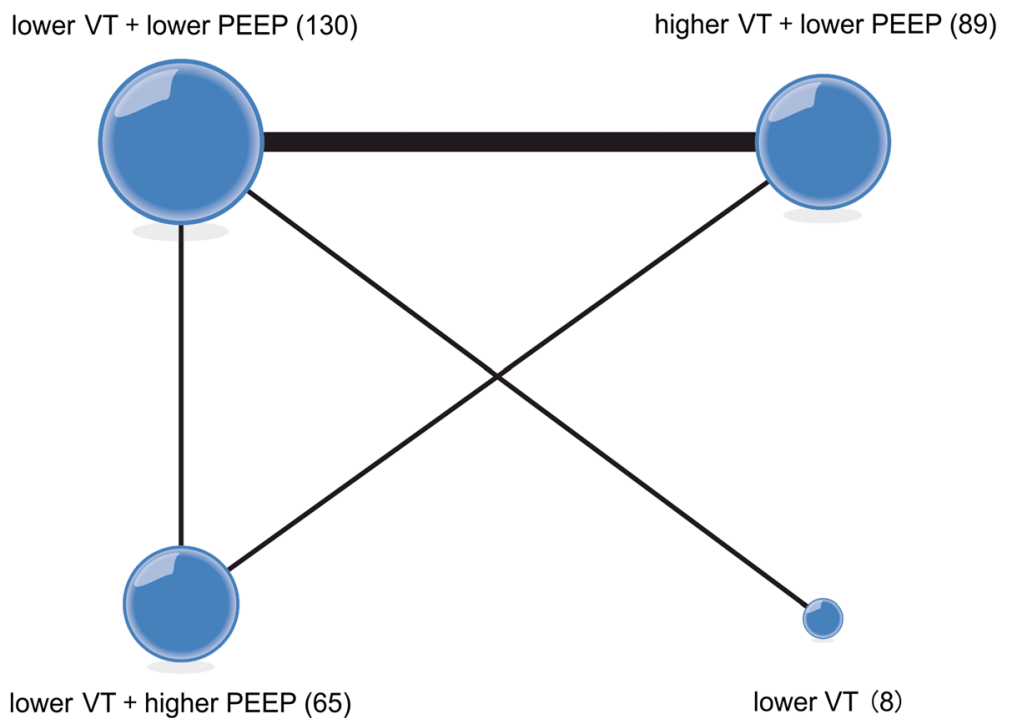

Fig. 2 Network of the comparisons of the partial pressure of arterial oxygen/fraction of inspired oxygen ratio in the Bayesian network meta-analysis. The size of a given node is proportional to the number of patients (in parentheses) randomized to receive the treatment. The width of each line is proportional to the number of trials (specified next to the line) comparing the connected treatments. PEEP positive end-expiratory pressure, VT tidal volume

\section{Length of ICU stay}

Three articles reported on the secondary outcome of the length of ICU stay $[24,28,33]$, and these studies examined three ventilation strategies (Fig. 6). We chose a fixed-effects model (Additional file 3C) to evaluate the MDs in the overall effect sizes. MD values and 95\% confidence intervals of various ventilation strategies are shown in Additional file 4B.

For probability ranking: strategy A (lower VT + lower PEEP) was associated with a shorter length of ICU stay; and the probability of strategy $\mathrm{A}$ holding the top ranking was $98.7 \%$. Strategy B (higher VT + lower PEEP) was estimated to be the worst strategy in terms of the length of ICU stay (Additional file 5C).

For direct and indirect comparison: compared to ventilation strategies $\mathrm{B}$ (higher VT + lower PEEP) and C (lower VT + higher PEEP), strategy A (lower VT + lower PEEP) was associated with a shorter length of ICU stay, and the respective MDs (95\% confidence intervals) were $-1.9(-2.2,-1.6)$ and $-1(-1.87,-0.124)$ (Fig. 7).

\section{Other outcomes}

Only one study [31] reported on the length of hospital stay, and two studies $[4,33]$ reported on the number of

$$
\begin{aligned}
& \text { Comparison Mean Difference }(95 \% \mathrm{Crl}) \\
& \begin{array}{ll|l}
\text { lower VT + lower PEEP vs lower VT + higher PEEP } & - & *-46.2(-78.6,-13.7) \\
\text { higher VT + lower PEEP vs lower VT + higher PEEP } & - & *-60.9(-98.6,-23.1)
\end{array} \\
& \text { lower VT vs lower VT + higher PEEP —_ } \\
& \Gamma \\
& 300 \\
& 0
\end{aligned}
$$

Fig. 3 Mean difference in the partial pressure of arterial oxygen/fraction of inspired oxygen $\left(\mathrm{PaO}_{2} / \mathrm{FIO}_{2}\right)$ ratio relative to the $\mathrm{PaO}_{2} / \mathrm{FIO}_{2}$ ratio of ventilation strategy $\mathrm{C}$ based on Bayesian network meta-analysis. $\mathrm{Crl}$ credible interval for Bayesian network meta-analysis. The mean difference (MD) was estimated from a Bayesian random-effects model of $\mathrm{PaO}_{2} / \mathrm{FIO}_{2}$ ratios in the network. "The range of $95 \%$ confidence intervals does not contain zero. MD <0 favors strategy C. PEEP positive end-expiratory pressure, VT tidal volume 


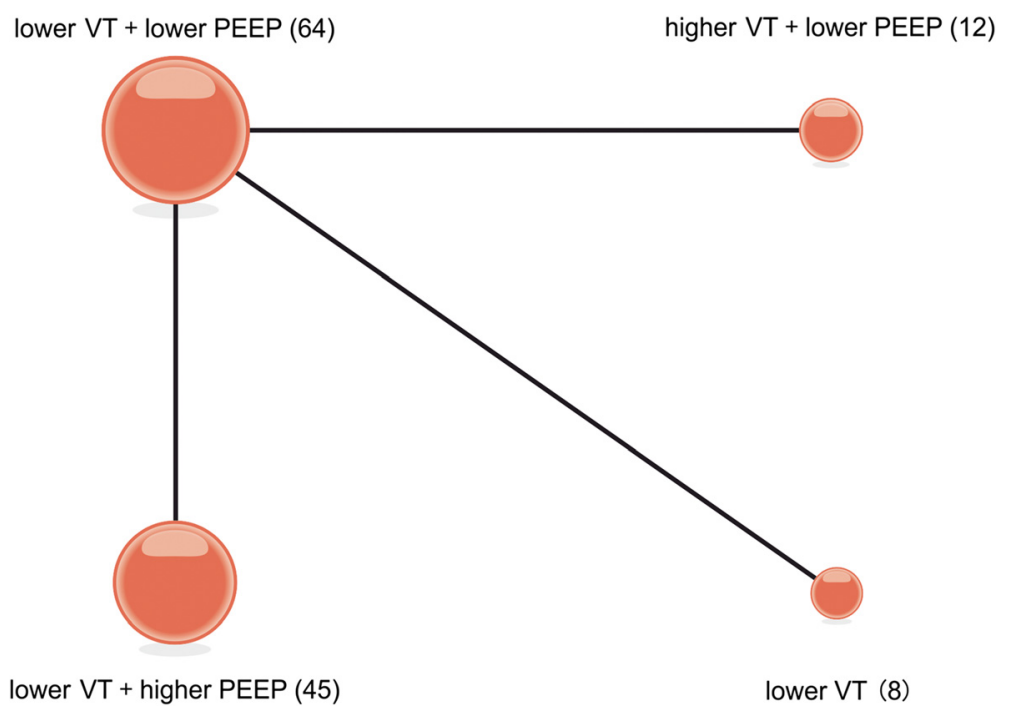

Fig. 4 Network of the comparisons of pulmonary compliance in the Bayesian network meta-analysis. The size of a given node is proportional to the number of patients (in parentheses) randomized to receive the treatment. The width of each line is proportional to the number of trials (specified next to the line) comparing the connected treatments. PEEP positive end-expiratory pressure, VT tidal volume

deaths. Unfortunately, certain ventilation strategies were isolated from the remaining ventilation strategies in these studies; therefore, the aforementioned outcomes could not be examined via network meta-analysis.

\section{Discussion}

Serpa Neto et al. [8] published a traditional pairwise meta-analysis on ventilation strategies for patients without ALI or ARDS in 2012; this meta-analysis applied no restrictions on the setting (ICU or operating room). However, considering the effect of the surgical procedure, ventilation during an operation and ventilation in the ICU are different, and this difference could lead to heterogeneous results. Therefore, we included only randomized controlled trials of ICU patients without ALI or ARDS. This approach renders this meta-analysis more purposeful and scientific.

However, network meta-analysis has several shortcomings. It is difficult to understand its methodological aspects. This method is not perfect and poses various challenges; for instance, we should carefully assess both conceptual and statistical heterogeneity as well as incoherence between included studies [34]. Furthermore, the results of a network meta-analysis are presented in two ways: probability ranking and the results of combined direct and indirect comparisons. The estimates of treatment effects should be interpreted with caution due to their uncertainty because treatment rankings or probabilities can be

\section{Comparison \\ Mean Difference (95\% Crl)
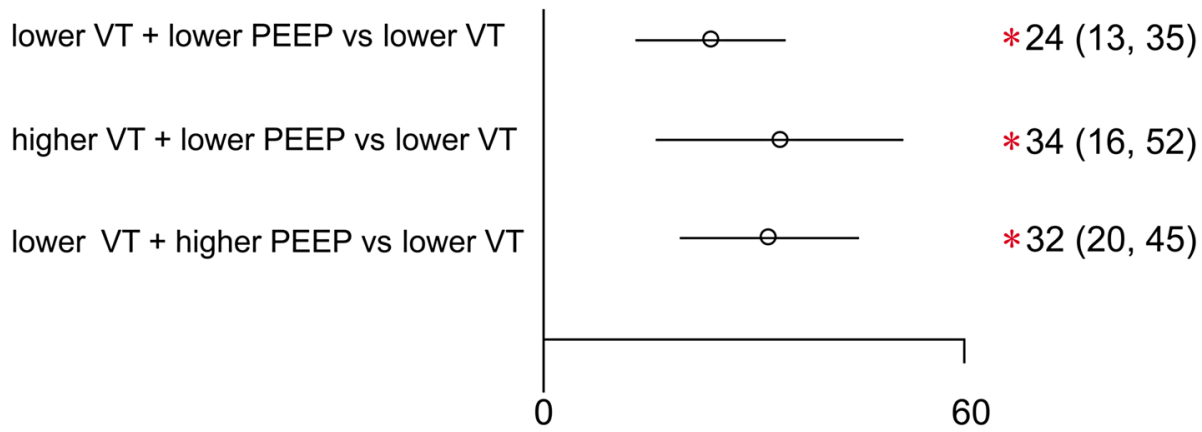

Fig. 5 Mean deviance in pulmonary compliance relative to strategy D based on Bayesian network meta-analysis. Crl credible interval for Bayesian network meta-analysis. The mean difference $(M D)$ was estimated from a Bayesian random-effects model of the pulmonary compliances in the network. "The range of $95 \%$ confidence intervals does not contain zero. MD >0 favors strategies A, B and C. PEEP positive end-expiratory pressure, $V T$ tidal volume 


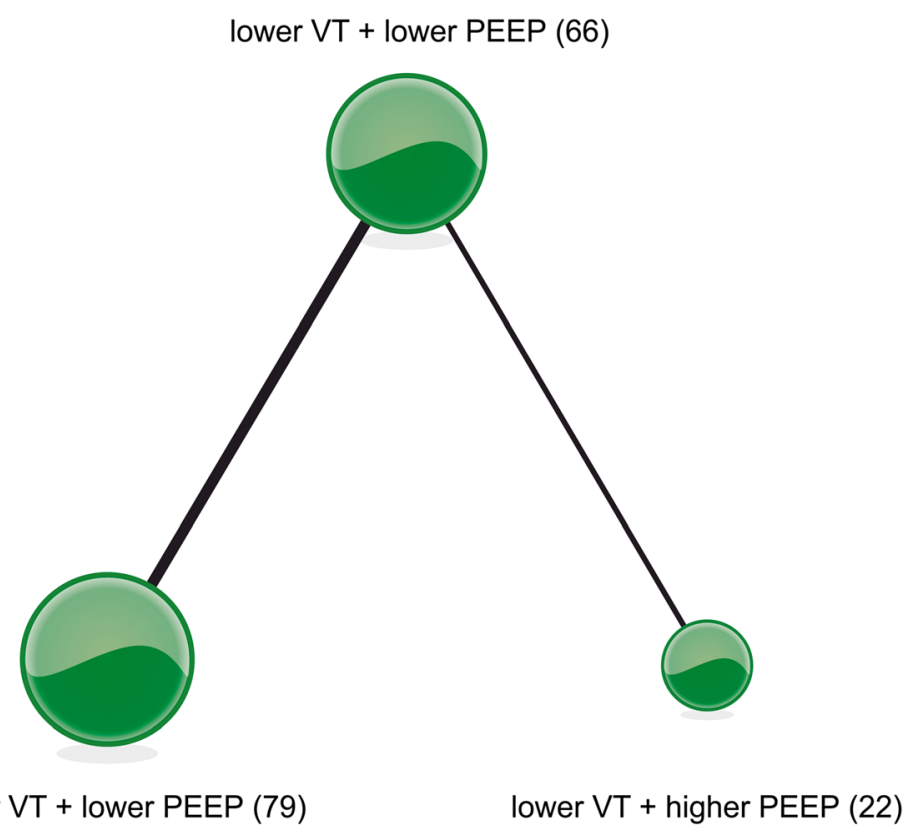

Fig. 6 Network of the comparisons of the length of ICU stay in the Bayesian network meta-analysis. The size of a given node is proportional to the number of patients (in parentheses) randomized to receive the treatment. The width of each line is proportional to the number of trials (specified next to the line) comparing the connected treatments. PEEP positive end-expiratory pressure, $V T$ tidal volume

misleading [34], whereas a combined analysis of direct and indirect evidence produces more meaningful results based on published studies.

In this study, the $\mathrm{PaO}_{2} / \mathrm{FIO}_{2}$ ratio was the primary outcome. Probability ranking showed that ventilation strategy C (lower VT + higher PEEP) was associated with the greatest increase in oxygenation; in contrast, ventilation strategy D (lower VT+ ZEEP) ranked last and was associated with the lowest $\mathrm{PaO}_{2} / \mathrm{FIO}_{2}$ ratio among all of the ventilation strategies examined. Moreover, based on direct and indirect comparisons, compared to strategies A (lower $\mathrm{VT}+$ lower PEEP), B (higher VT + lower PEEP), and D (lower VT + ZEEP), ventilation strategy C (lower VT + higher PEEP) was the most effective ventilation strategy in terms of the $\mathrm{PaO}_{2} / \mathrm{FiO}_{2}$ ratio, and these differences in effectiveness were statistically significant.

Ventilator-associated lung injury is a common clinical complication in critically ill patients receiving mechanical ventilation [35]. An increased tidal volume can overstretch the alveoli; this process is termed volutrauma, and overstretching is the main reason for ventilatorassociated lung injury [35, 36]. Although lower tidal volumes can cause distal alveolar collapse and inadequate ventilation, high PEEP can significantly compensate for this shortcoming by stimulating recruitment of collapsed alveoli to alleviate focal atelectasis, increase alveolar ventilation, and reduce the alveolar-arterial oxygen difference, thereby effectively relieving the occurrence of

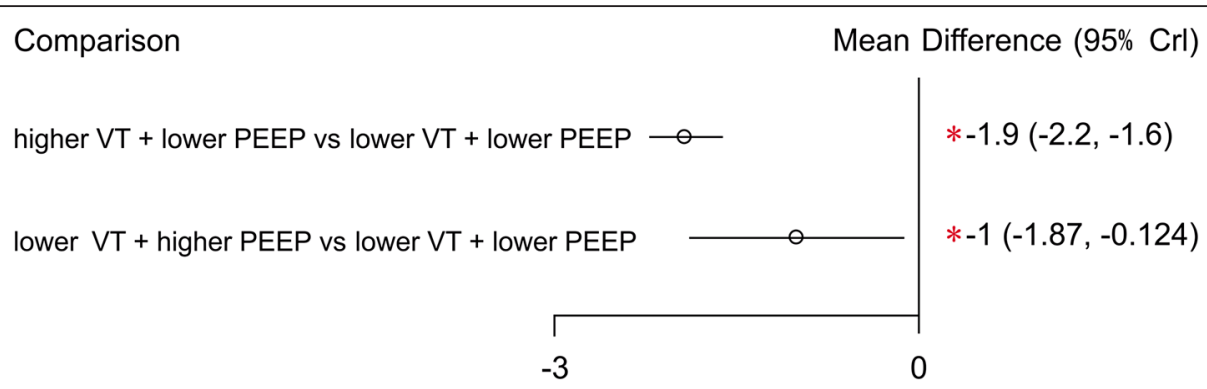

Fig. 7 Mean difference in the length of ICU stay relative to strategy A based on Bayesian network meta-analysis. Cl credible interval for Bayesian network meta-analysis. The mean difference $(M D)$ was estimated from a Bayesian random-effects model of the lengths of ICU stay in the network. ${ }^{*}$ The range of $95 \%$ confidence intervals does not contain zero. MD $<0$ favors strategy A. PEEP positive end-expiratory pressure, VT tidal volume 
pulmonary shunting and ensure the delivery of arterial oxygen [37, 38]. Simultaneously, a reduced tidal volume can reduce ventilator-associated lung injury [37-39]. These phenomena could explain how ventilation strategy $\mathrm{C}$ (lower VT + higher PEEP) increased the $\mathrm{PaO}_{2} / \mathrm{FiO}_{2}$ ratio and restored oxygen saturation.

Pulmonary compliance was a secondary outcome in our study. Probability ranking indicated that ventilation strategy B (higher VT + lower PEEP) was associated with the highest pulmonary compliance but that ventilation strategy D (lower VT+ ZEEP) was associated with the lowest pulmonary compliance. Moreover, based on direct and indirect comparisons, we found that compared to strategies A (lower VT + lower PEEP), B (higher VT + lower PEEP), and C (lower VT + higher PEEP), strategy $\mathrm{D}$ (lower VT + ZEEP) was significantly associated with the lowest lung compliance.

The finding that ventilation strategy B (higher VT + lower PEEP) was associated with the highest pulmonary compliance could be related to the following reasons: (1) a high tidal volume during mechanical ventilation can expand small airways, fully open alveoli, and reduce intraoperative focal atelectasis, and PEEP can further increase the stability of opened alveoli and enhance pulmonary compliance [40]; (2) PEEP can hold alveoli open at the end of exhalation, significantly increase functional residual capacity, enable the alveoli to begin to expand at a high functional residual capacity, avoid excessive expansion and contraction of the lungs during inhalation and exhalation, and reduce the destruction of lung tissue and its interstitial structure, and damage to the alveoli. Consequently, PEEP maintains the elastic recoil of the lung and enhances lung compliance [38, 40, 41].

Ventilation strategy D (lower VT + ZEEP) was associated with the lowest pulmonary compliance and the smallest increase in oxygenation. The mechanism underlying this association could be that a lower tidal volume during mechanical ventilation causes the distal alveolar and small airways to close, resulting in alveolar collapse, insufficient ventilation, increased intrapulmonary shunting, and a decreased $\mathrm{PaO}_{2} / \mathrm{FIO}_{2}$ ratio. This mechanism is supported by the findings of HU et al. [42]. Hedenstierna et al. [43] also found that atelectasis and airway closure can explain $75 \%$ of the deterioration in $\mathrm{PaO}_{2}$ during mechanical ventilation. Under conditions of alveolar collapse and reduced functional residual capacity resulting from a low tidal volume, lung compliance cannot be enhanced effectively. This result is consistent with the results presented by Bruno Enekvist: low pulmonary compliance may be correlated with an increased number of collapsed alveoli [44, 45].

There were three reports on the duration of ICU stay in our network meta-analysis, and those reports examined ventilation strategies A (lower VT+lower PEEP), B (higher VT+lower PEEP) and C (lower VT+higher PEEP). Compared to strategies B (higher $\mathrm{VT}+$ lower PEEP) and C (lower VT + higher PEEP), strategy A (lower $\mathrm{VT}+$ lower PEEP) was significantly associated with a shorter duration of ICU stay. One reason for this benefit of strategy A is that lower tidal volume combined with lower PEEP can leave areas of alveolar collapse unaltered, avoiding cyclic recruitment/de-recruitment of distal lung units, while avoiding hyperinflation in normal lung regions, thus reducing end-inspiratory stress and lung inflammation and consequently minimizing ventilatorinduced lung injury [46-48]. In addition, the use of a low tidal volume together with lower PEEP $\left(5 \mathrm{~cm} \mathrm{H}_{2} 0\right)$ in animal models can result in improved oxygenation [49]. This finding is consistent with the results that were described by Karsten et al. [50], who stated that lower PEEP combined with low VT prevents deoxygenation when there is pneumoperitoneum and leads to a lower atelectasis score based on computed tomography up to 2 hours postoperatively.

This study had several limitations. The initial aim of this article was focused on the development of lung injury, overall survival, the incidence of pulmonary infection and atelectasis, the length of ICU and hospital stay, time to extubation, the $\mathrm{PaO}_{2} / \mathrm{FIO}_{2}$ ratio, and pulmonary compliance; however, because of the small number of research articles that we included, there were no uniform outcome measures in our study. Aside from $\mathrm{PaO}_{2} / \mathrm{FIO}_{2}$ ratio and pulmonary compliance, we extracted only one article on hospital length of stay and only two articles on overall survival. Moreover, the original results were incomplete, which indicates that this meta-analysis could only produce relatively simple results rather than comprehensive and diverse results. We hope that there will be additional clinical research focused on the development of lung injury in the future.

\section{Conclusion}

The results of this meta-analysis showed that for ICU patients without ALI or ARDS, strategy C (lower VT + higher PEEP) was associated with the highest $\mathrm{PaO}_{2} / \mathrm{FiO}_{2}$ ratio; strategy $\mathrm{B}$ (higher VT + lower PEEP) was superior to the other strategies in improving pulmonary compliance; strategy A (lower VT + lower PEEP) was associated with a shorter length of ICU stay; and strategy D (lower $\mathrm{VT}+\mathrm{ZEEP})$ was associated with the lowest $\mathrm{PaO}_{2} / \mathrm{FiO}_{2}$ ratio and pulmonary compliance.

\section{Key messages}

- Strategy C (lower VT + higher PEEP) was associated with the highest $\mathrm{PaO}_{2} / \mathrm{FiO}_{2}$ ratio in ICU patients without ALI or ARDS 
- Strategy B (higher VT + lower PEEP) was superior to the other strategies in improving pulmonary compliance in ICU patients without ALI or ARDS

- Strategy D (lower VT + ZEEP) was associated with the lowest $\mathrm{PaO}_{2} / \mathrm{FiO}_{2}$ ratio and pulmonary compliance in ICU patients without ALI or ARDS

\section{Additional files}

Additional file 1: Appendix 1. Summary of excluded articles. (DOC 19 kb) Additional file 2: Appendix 2A. The $\mathrm{PaO}_{2} / \mathrm{FlO}_{2}$ ratio effect estimates from multiple treatment meta-analysis compared with direct and indirect estimates, based on back-calculated, and pairwise meta-analyses. Direct and indirect estimates of effect and the corresponding Bayesian $\mathcal{R}^{2}$ values for inconsistency were calculated. The $R^{2}$ values from pooled pairwise meta-analysis for heterogeneity were also calculated. Appendix 2B. The ICU length of hospital effect estimates from multiple treatment meta-analysis compared with direct and indirect estimates, based on back-calculated, and pairwise meta-analyses. Direct and indirect estimates of effect and the corresponding Bayesian $R^{2}$ values for inconsistency were calculated. The $P^{2}$ values from pooled pairwise meta-analysis for heterogeneity were also calculated. (DOC $80 \mathrm{~kb}$ )

Additional file 3: Appendix 3A. Model fit for $\mathrm{PaO}_{2} / \mathrm{FlO}_{2}$ ratio results. Appendix 3B. Model fit for compliance results. Appendix 3C. Model fit for ICU length of hospital stay results. (DOC $27 \mathrm{~kb}$ )

Additional file 4: Appendix 4A. Pooled odds ratios for $\mathrm{PaO} 2 / \mathrm{FlO} 2$ ratio. Appendix 4B. Pooled odds ratios for ICU length of hospital stay and pooled mean difference for pulmonary compliance. (DOC $32 \mathrm{~kb}$ )

Additional file 5: Appendix 5A. Rankings based on simulations in terms of $\mathrm{PaO} 2 / \mathrm{FlO} 2$ ratio. Appendix 5B. Rankings based on simulations in terms of compliance. Appendix 5C. Rankings based on simulations in terms of ICU length of hospital stay. (DOC $28 \mathrm{~kb}$ )

\section{Abbreviations}

ALI, acute lung injury; ARDS, acute respiratory distress syndrome; DIC, deviance information criterion; ICU, intensive care unit; $\mathrm{MD}$, mean difference; $\mathrm{PaO}_{2} / \mathrm{FiO}_{2}$ ratio, partial pressure of arterial oxygen/fraction of inspired oxygen; PEEP, positive end-expiratory pressure; RM, recruitment maneuver; $V T$, tidal volume; ZEEP, zero end-expiratory pressure

\section{Authors' contributions}

CW, EL and WW searched the scientific literature and drafted the manuscript. $L G, C C, W H$, and AW performed the statistical analyses and revised the manuscript. NZ, LBG, HT, and YW participated in data interpretation and drafted the report. CW and EL conceived of the study and contributed data. EL made important revisions to the draft report. All authors have read and approved the final version of the manuscript.

\section{Competing interests}

The authors declare that they have no competing interests.

Received: 26 January 2016 Accepted: 29 June 2016

Published online: 22 July 2016

\section{References}

1. The Acute Respiratory Distress Syndrome Network. Ventilation with lower tidal volumes as compared with traditional tidal volumes for acute lung injury and the acute respiratory distress syndrome. $\mathrm{N}$ Engl J Med. 2000;342(18):1301-8

2. Brun-Buisson C, Minelli C, Bertolini G, Brazzi L, Pimentel J, Lewandowski K, et al. Epidemiology and outcome of acute lung injury in European intensive care units: results from the ALIVE study. Intensive Care Med. 2004;30(1):51-1.

3. Dellinger RP, Carlet JM, Masur H, Gerlach H, Calandra T, Cohen J, et al. Surviving Sepsis Campaign Management Guidelines Committee. Surviving Sepsis Campaign guidelines for management of severe sepsis and septic shock. Crit Care Med. 2004;32:858-73.
4. Determann RM, Royakkers A, Wolthuis EK, Vlaar AP, Choi G, Paulus F, et al. Ventilation with lower tidal volumes as compared with conventional tidal volumes for patients without acute lung injury: a preventive randomized controlled trial. Crit Care. 2010;14:R1.

5. Wongsurakiat $P$, Pierson DJ, Rubenfeld GD. Changing pattern of ventilator settings in patients without acute lung injury: changes over 11 years in a single institution. Chest. 2004;126(4):1281-91.

6. Gajic O, Dara SI, Mendez JL, Adesanya AO, Festic E, Caples SM, et al. Ventilator-associated lung injury in patients without acute lung injury at the onset of mechanical ventilation. Crit Care Med. 2004;32:1817-24.

7. Schultz MJ, Haitsma JJ, Slutsky AS, Gajic O. What tidal volumes should be used in patients without acute lung injury? Anesthesiology. 2007:106(6):1226-31.

8. Serpa Neto A, Cardoso SO, Manetta JA, Pereira VG, Espósito DC, Pasqualucci Mde $\mathrm{O}$, et al. Association between use of lung-protective ventilation with lower tidal volumes and clinical outcomes among patients without acute respiratory distress syndrome: a meta-analysis. JAMA. 2012;308(16):1651-9.

9. Mills EJ, Bansback N, Ghement I, Thorlund K, Kelly S, Puhan MA, et al. Multiple treatment comparison meta-analyses: a step forward into complexity. Clin Epidemiol. 2011;3:193-202.

10. Caldwell DM, Ades AE, Higgins JP. Simultaneous comparison of multiple treatments: combining direct and indirect evidence. BMJ. 2005;331:897-900

11. Moher D, Liberati A, Tetzlaff J, Altman DG, PRISMA Group. Preferred reporting items for systematic reviews and meta-analyses: the PRISMA statement. PLoS Med. 2009;6:e1000097.

12. Santa Cruz R, Rojas Jl, Nervi R, Heredia R, Ciapponi A. High versus low positive end-expiratory pressure (PEEP) levels for mechanically ventilated adult patients with acute lung injury and acute respiratory distress syndrome. Cochrane Database Syst Rev. 2013;6:CD009098.

13. Treschan TA, Kaisers W, Schaefer MS, Bastin B, Schmalz U, Wania V, et al. Ventilation with low tidal volumes during upper abdominal surgery does not improve postoperative lung function. Br J Anaesth. 2012;109:263-71.

14. Salanti G, Higgins JP, Ades AE, loannidis JP. Evaluation of networks of randomized trials. Stat Methods Med Res. 2008;17:279-301.

15. Higgins JP, Whitehead A. Borrowing strength from external trials in a meta-analysis. Stat Med. 1996;15:2733-49.

16. Salanti G, Ades AE, loannidis JP. Graphical methods and numerical summaries for presenting results from multiple-treatment meta-analysis: an overview and tutorial. J Clin Epidemiol. 2011;64:163-71.

17. Van Valkenhoef G, Lu G, de Brock B. Automating network meta-analysis. Res Syn Meth. 2012;3:285-99.

18. Dogliotti A, Paolasso E, Giugliano RP. Current and new oral antithrombotics in non-valvular atrial fibrillation: a network meta-analysis of 79808 patients. Heart. 2014;100:396-4052.

19. Dias S, Sutton AJ, Ades AE, Welton NJ. Evidence synthesis for decision making 2: a generalized linear modeling framework for pairwise and network meta-analysis of randomized controlled trials. Med Decis Making. 2013;33:607-17.

20. Simillis C, Li T, Vaughan J, Becker LA, Davidson BR, Gurusamy KS. Methods to decrease blood loss during liver resection: a network meta-analysis. Cochrane Database Syst Rev. 2014;4:CD010683.

21. Brooks SP, Gelman A. General methods for monitoring convergence of iterative simulations. J Comput Graph Stat. 1998;7:434-55.

22. Dias S, Welton NJ, Caldwell DM, Ades AE. Checking consistency in mixed treatment comparison meta-analysis. Stat Med. 2010;29:932-44.

23. Higgins JP, Thompson SG, Deeks JJ, Altman DG. Measuring inconsistency in meta-analyses. BMJ. 2003:327:557-60.

24. Lee PC, Helsmoortel CM, Cohn SM, Fink MP. Are low tidal volumes safe? Chest. 1990;97(2):430-4.

25. Borges DL, Nina VJ, Costa Mde A, Baldez TE, Santos NP, Lima IM, et al. Effects of different PEEP levels on respiratory mechanics and oxygenation after coronary artery bypass grafting. Rev Bras Cir Cardiovasc. 2013;28(3):380-5.

26. Dyhr $\mathrm{T}$, Laursen $\mathrm{N}$, Larsson A. Effects of lung recruitment maneuver and positive end-expiratory pressure on lung volume, respiratory mechanics and alveolar gas mixing in patients ventilated after cardiac surgery. Acta Anaesthesiol Scand. 2002:46(6):717-25.

27. Chaney MA, Nikolov MP, Blakeman BP, Bakhos M. Protective ventilation attenuates postoperative pulmonary dysfunction in patients undergoing cardiopulmonary bypass. J Cardiothorac Vasc Anesth. 2000;14(5):514-8.

28. Wrigge $H$, Uhlig U, Baumgarten G, Menzenbach J, Zinserling J, Ernst $M$, et al Mechanical ventilation strategies and inflammatory responses to cardiac 
surgery: a prospective randomized clinical trial. Intensive CareMed. 2005;31(10):1379-87.

29. Koutsoukou A, Perraki H, Raftopoulou A, Koulouris N, Sotiropoulou C, Kotanidou A, et al. Respiratory mechanics in brain-damaged patients. Intensive Care Med. 2006;32(12):1947-54.

30. Good Jr JT, Wolz JF, Anderson JT, Dreisin RB, Petty TL. The routine use of positive end-expiratory pressure after open heart surgery. Chest. 1979;76(4):397-400.

31. Marvel SL, Elliott CG, Tocino I, Greenway LW, Metcalf SM, Chapman RH. Positive end-expiratory pressure following coronary artery bypass grafting. Chest. 1986;90(4):537-41.

32. Zupancich E, Paparella D, Turani F, Munch C, Rossi A, Massaccesi S, et al. Mechanical ventilation affects inflammatory mediators in patients undergoing cardiopulmonary bypass for cardiac surgery: a randomized clinical trial. J Thorac Cardiovasc Surg. 2005;130(2):378-83.

33. PinheirodeOliveira R, Hetzel MP, dos Anjos Silva M, Dallegrave D, Friedman G. Mechanical ventilation with high tidal volume induces inflammation in patients without lung disease. Crit Care. 2010;14(2):R39.

34. Mills EJ, Thorlund K, loannidis JP. Demystifying trial networks and network meta-analysis. BMJ. 2013;14:f2914.

35. Plötz FB, Slutsky AS, van Vught AJ, Heijnen CJ. Ventilator-induced lung injury and multiple system organ failure: a critical review of facts and hypotheses. Intensive Care Med. 2004;30(10):1865-72.

36. Carney D, DiRocco J, Nieman G. Dynamic alveolar mechanics and ventilatorinduced lung injury. Crit Care Med. 2005;33(3 Suppl):S122-8.

37. Choi G, Wolthuis EK, Bresser P, Levi M, van der Poll T, Dzoljic M, et al. Mechanical ventilation with lower tidal volumes and positive end-expiratory pressure prevents alveolar coagulation in patients without lung injury. Anesthesiology. 2006;105:689-95.

38. Wolthuis EK, Choi G, Dessing MC, Bresser P, Lutter R, Dzoljic M, et al. Mechanical ventilation with lower tidal volumes and positive end-expiratory pressure prevents pulmonary inflammation in patients without preexisting lung injury. Anesthesiology. 2008;108:46-54.

39. Rothen HU, Sporre B, Engberg G, Wegenius G, Reber A, Hedenstierna G. Prevention of atelectasis during general anaesthesia. Lancet. 1995;345:1387-91.

40. Almarakbi WA, Fawzi HM, Alhashemi JA. Effects of four intraoperative ventilatory strategies on respiratory compliance and gas exchange during laparoscopic gastric banding in obese patients. Br J Anaesth. 2009;102:862-8.

41. Zhao Z, Steinmann D, Frerichs I, Guttmann J, Möller K. PEEP titration guided by ventilation homogeneity: a feasibility study using electrical impedance tomography. Crit Care. 2010;14:R8.

42. Rothen HU, Sporre B, Engberg G, Wegenius G, Hedenstierna G. Airway closure, atelectasis and gas exchange during general anaesthesia. Br J Anaesth. 1998;81(5):681-6.

43. Hedenstierna G. Alveolar collapse and closure of airways: regular effects of anaesthesia. Clin Physiol Funct Imaging. 2003;23(3):123-9.

44. Pelosi P, Croci M, Ravagnan I, Tredici S, Pedoto A, Lissoni A, et al. The effects of body mass on lung volumes, respiratory mechanics, and gas exchange during general anesthesia. Anesth Analg. 1998;87(3):654-60.

45. Enekvist B, Bodelsson M, Johansson A. Increased apparatus dead space and tidal volume increase blood concentrations of oxygen and sevoflurane in overweight patients: a randomised controlled clinical study. Eur J Anaesthesiol. 2011:28(5):382-6.

46. Samary CS, Santos RS, Santos CL, Felix NS, Bentes M, Barboza T, et al. Biological impact of transpulmonary driving pressure in experimental acute respiratory distress syndrome. Anesthesiology. 2015;123(2):423-33.

47. Güldner A, Kiss T, Serpa Neto A, Hemmes SN, Canet J, Spieth PM, et al. Intraoperative protective mechanical ventilation for prevention of postoperative pulmonary complications: a comprehensive review of the role of tidal volume, positive end-expiratory pressure, and lung recruitment maneuvers. Anesthesiology. 2015;123(3):692-713.

48. Chu EK, Whitehead T, Slutsky AS. Effects of cyclic opening and closing at low and high volume ventilation on bronchoalveolar lavage cytokines Crit Care Med. 2004;32(1):168-74.

49. Dreyfuss D, Soler P, Basset G, Saumon G. High inflation pressure pulmonary edema: respective effects of high airway pressure, high tidal volume, and positive end-expiratory pressure. Am Rev Respir Dis. 1988;137(5):1159-64.

50. Karsten J, Luepschen H, Grossherr M, Bruch HP, Leonhardt S, Gehring H, et al. Effect of intraoperative use of positive end expiratory pressure on lung atelectasis during laparoscopic cholecystectomy. Acta Anaesthesiol Scand. 2011;55(7):878-86

\section{Submit your next manuscript to BioMed Central and we will help you at every step:}

- We accept pre-submission inquiries

- Our selector tool helps you to find the most relevant journal

- We provide round the clock customer support

- Convenient online submission

- Thorough peer review

- Inclusion in PubMed and all major indexing services

- Maximum visibility for your research

Submit your manuscript at www.biomedcentral.com/submit 